\title{
A Rare Etiology of Pericarditis, Brucella spp.
}

Nadir Bir Perikardit Etiyolojisi, Brucella spp.

\section{Abstract}

In brucellosis, pericarditis is usually a complication associated with endocarditis, and isolated pericarditis is rare. In this paper, we present a rare case of isolated pericarditis due to brucellosis without endocarditis, associated with cardiac signs and symptoms.

Keywords: brucellosis; cardiovascular system; isolated pericarditis

\section{Öz}

Brusellozda perikardit genellikle endokardit ile birlikte görülen bir komplikasyondur ve izole perikardit nadir görülür. Bu yazıda, kardiyak belirti ve bulgularla seyreden, endokarditin eșlik etmediği bruselloza bağı nadir bir izole perikardit vakası sunulmaktadır.

Anahtar Sözcükler: bruselloz; izole perikardit; kardiyovasküler sistem
Tuba Tatli Kis', Mehmet Kis²

1 Department of Infectious Diseases and Clinical Microbiology, Silopi State Hospital

2 Department of Cardiology, Silopi State Hospital

Received/Gelis : 21.02.2020

Accepted/Kabul: 01.05.2020

DOI: 10.21673 /anadoluklin.692085

Corresponding author/Yazıșma yazarı Tuba Tatli Kis

Silopi Devlet Hastanesi, Enfeksiyon Hastalıkları ve Klinik Mikrobiyoloji, Sırnak, Turkey

E-mail: tubatatlii@hotmail.com

ORCID

Tuba Tatli Kis: 0000-0001-6952-3748 Mehmet Kis: 0000-0003-0775-8992 


\section{INTRODUCTION}

Brucellosis is one of the most common zoonotic diseases in the world. Globally, the Mediterranean Basin, India, Mexico, and Central and South America are areas of hyperendemic brucellosis (1). However, the disease is also seen in the Eastern and Southeastern Anatolia regions of Turkey (1). It is transmitted to humans by contact with fluids of infected animals and consumption of infected meat and unpasteurized dairy products. Accidental transmission is also possible in laboratories working with infected body fluids $(1,2)$. Because it can affect many organs and tissues, it can present with a wide range of clinical manifestations, making the diagnosis difficult. The most frequently affected systems are the musculoskeletal, gastrointestinal, genitourinary, hematological, and respiratory systems (2). Cardiovascular involvement is rare, having been reported in $1-2 \%$ of all cases $(1,3)$. The most common cardiovascular complication is endocarditis (4). Brucella endocarditis most frequently involves the aortic valve and less frequently the mitral valve. This is followed by myocarditis and pericarditis $(2,5)$. Pericarditis is a complication usually associated with endocarditis, and reports of isolated pericarditis are rare in the literature. Accordingly, in this paper we aimed to present a rare case of isolated pericarditis due to brucellosis presenting with cardiac signs and symptoms.

\section{CASE}

A 19-year-old male was admitted to the outpatient clinic with the complaints of severe chest pain, fever, joint pain, and weight loss for about one week. The patient had been living as a shepherd and had lost 5 kilograms in weight during the last month. The patient had occasional fever and joint pain, especially in the knee joint, and also a sharp chest pain starting in the last week. The chest pain was less severe when the patient leaned forward or while he was in a sitting position. He reported eating fresh cheese and a history of miscarriage in his animals. The physical examination revealed no pathological findings except for frotman. The laboratory findings (complete blood count and biochemical tests) were within normal levels (erythrocyte sedimentation rate: $63 \mathrm{~mm} / \mathrm{h}$, C-reactive protein [CRP]: $4.9 \mathrm{mg} / \mathrm{dL}$ ). The autoimmune markers were also within normal levels. His Brucella Rose Bengal test result was positive and Brucellosis Coombs test was 1/5120 positive. Two peripheral blood cultures were requested. Transthoracic echocardiography (TTE) was performed for the patient who had widespread ST elevation on electrocardiography (ECG). TTE showed normal left ventricle (LV) and right ventricle (RV) ejection fraction (EF), 1-2 degree mitral regurgitation, mitral valve prolapse, mild pericardial effusion with no evidence of compression in the posterior LV, and increased pericardial brightness (Figure 1). No vegetation/abscess/mass echogenicity was observed in the heart valves and papillary muscles. Computed tomography of the thorax also showed pericardial effusion (Figure 2). The peripheral blood cultures revealed Brucella spp. growth. The patient was diagnosed with $\mathrm{Bru}$ cella pericarditis and prescribed doxycycline $(2 \times 100$ $\mathrm{mg})$, rifampicin $(1 \times 600 \mathrm{mg})$, trimethoprim sulfamethoxazole (160/800 mg 2x1), and ibuprofen (3x400 $\mathrm{mg}$ ). The symptoms rapidly improved by the sixth day of antibiotherapy and no side effects occurred during the follow-up. He received antibiotherapy for a total of three months. In the third month, clinical and laboratory responses were obtained, and the follow-up TTE showed decreased pericardial brightness and regression in effusion. No recurrence was observed in the six-month follow-up after the end of the treatment.

\section{Report ethics}

Written informed consent was obtained from the patient for the publication of this case report and the figures included.

\section{DISCUSSION}

Brucellosis is one of the most common zoonotic diseases in Turkey. Unpasteurized dairy products are a particularly common source of human transmission (6). Risk groups include livestock farmers, slaughterhouse workers, veterinarians, and laboratory workers (7). Our patient reported both eating fresh cheese and a history of miscarriages in his animals, as well as being a shepherd.

Brucellosis as a systemic infection can affect many different organs and tissues. Therefore, it can present with a wide range of clinical signs and symptoms that 


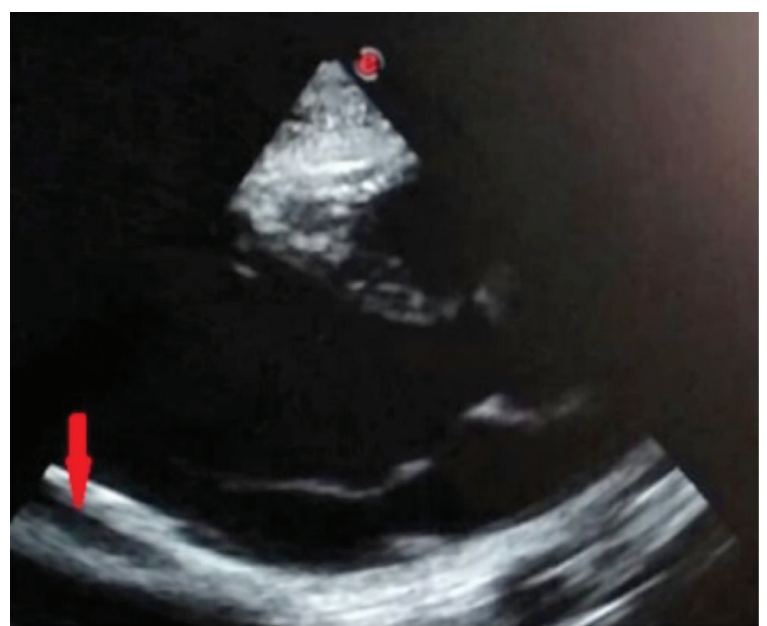

Figure 1. Echocardiography showing pericardial effusion in the posterior left ventricle and increased pericardial brightness

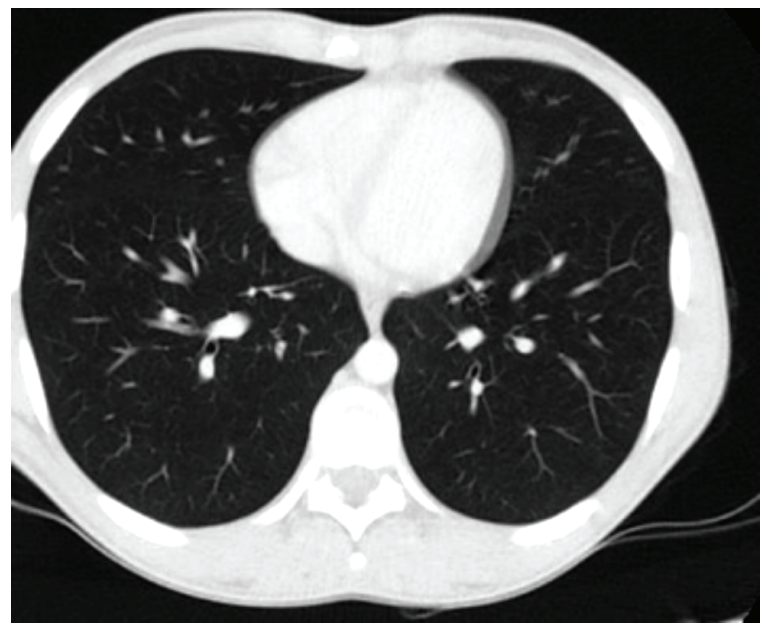

Figure 2. Thoracic computed tomography image showing pericardial effusion

can be confused with other diseases. It shows various clinical types, ranging from asymptomatic to lifethreatening. The most common symptoms are fever, sweating, headache, muscle pain, weakness, fatigue, and joint pain. It has recently been reported that the most common manifestations of brucellosis include fever (92.3\%), osteoarticular pain (46.2\%), and urinary tract symptoms (30.8\%) (8), while the most common complications are osteoarticular system complications (2). The bone marrow, spleen, and liver are the most frequently affected tissues and organs (9). Among endocarditis, pericarditis, and myocarditis, rarely seen in brucellosis (10), endocarditis constitutes the most common cardiovascular involvement, often affecting the aortic valve and, less frequently, the mitral valve. Cases of isolated Brucella pericarditis without endocarditis have rarely been reported in the literature $(3,6)$. A study of 530 cases of brucellosis in Spain found a cardiovascular complication rate of $1.5 \%$ and only one case of pericarditis without endocardial involvement (3). Taşova et al. examined 238 patients with brucellosis and found that only one patient had endocarditis while no patient had isolated pericarditis (5). A retrospective study of 1028 cases of brucellosis reported cardiac involvement in seven patients $(0.7 \%)$, all diagnosed with endocarditis (9).

Chest pain, dyspnea, and fever are common in patients with pericarditis. Physical examination reveals pericardial frotman in approximately half of the cases (10). Similarly, our patient was admitted with fever, joint pain and chest pain, and frotman was detected in the physical examination.

The diagnosis of Brucella pericarditis is made based on the clinical and epidemiological characteristics of the disease, symptoms of the patient, findings of electrocardiography and echocardiography, results of serological tests, and isolation of the microorganism by blood, bone marrow or pericardial fluid culture (11). In our case, peripheral blood cultures revealed Brucella spp. growth. We did not perform pericardiocentesis as it is not required in cases of Brucella pericarditis in the absence of cardiac tamponade (12). The diagnosis of isolated pericarditis due to Brucella spp. was made based on the patient's epidemiological history (working as a shepherd and fresh cheese consumption), compatible clinical findings, bacterial growth in the blood cultures, increased pericardial brightness, minimal pericardial effusion, and high-titer Brucellosis Coombs test (1/5120) positivity.

In the treatment of brucellosis, double and, in some cases, triple antibiotherapy is administered. Monotherapy is not recommended due to resistance and relapses. In a case of pericarditis due to brucellosis, Zorlu et al. reported complete recovery after treatment with doxycycline and rifampin (13). In another case, recovery was achieved soon after initiating combined treatment with anti-inflammatory and antibiotic medication (14). Our patient received antibiotherapy and additional anti-inflammatory therapy for 3 months. He was completely asymptomatic after 3 months, with decreased ST elevation in ECG and decreased pericardial 
brightness in echocardiography. The sedimentation and CRP levels returned to normal levels. In brucellosis with isolated pericarditis, survival rates are high and complete recovery is possible through early antibiotic treatment with appropriate drug dosage and combination, as in our patient.

\section{CONCLUSION}

Isolated pericarditis is one of the rare complications of brucellosis. It may be clinically asymptomatic or manifest with chest pain and ECG changes mimicking ischemic heart disease. The diagnosis is made based on patient anamnesis, compatible clinical findings, Brucella serum tube agglutination tests, and/or blood culture positivity and TTE findings. In Brucella pericarditis, pericardial fluid culture is not necessary for the diagnosis and pericardiocentesis should be performed only in patients with cardiac tamponade. The pericarditis treatment is carried out with antibiotherapy regimens used in other cases of brucellosis. Antibiotherapy can be continued for six weeks to three months and, in selected cases, additional use of anti-inflammatory drugs may be beneficial. Clinical suspicion, adequate antibiotic therapy and multidisciplinary approach can provide complete recovery in cases of brucellosis that might otherwise result in death from heart disease. Finally, brucellosis should be considered and ruled out in the differential diagnosis of patients with pericarditis who live in endemic areas.

\section{REFERENCES}

1. Pappas G, Akritidis N, Bosilkovski M, Tsianos E. Medical progress: brucellosis. N Engl J Med. 2005;352(22):232536.

2. Young J. Brucella species. In: Mandell GL, Bennett JE, Dolin R (ed.), Principles and Practice of Infectious Diseases, 7. ed. Philadelphia: Elsevier Churchill Livingstone; 2010:2921-5.

3. Colmenero JD, Reguera JM, Martos F, Sánchez-De-Mora D, Delgado M, Causse M, et al. Complications associated with Brucella melitensis infection: a study of 530 cases. Medicine (Baltimore). 1996;75(4):195-211.

4. Ataman Hatipoglu C, Yetkin A, Ertem GT, Tulek N. Unusual clinical presentations of brucellosis. Scand J Infect Dis. 2004;36(9):694-7.
5. Taşova Y, Saltoğlu N, Yılmaz G, Ünal S, Aksu HS. Brucellosis: an evaluation of clinical, laboratory and treatment features of 238 adult cases. Turk J Infect. 1998;12:307-12.

6. Gomez-Huelgas R, De Mora M, Parras JJ, Nuño E, SanRoman CM. Brucella and acute pericarditis: fortuitous or causal association. J Infect Dis. 1986;154(3):544.

7. McDermott JJ, Arimi SM. Brucellosis in sub-Saharan Africa: epidemiology, control and impact. Vet Microbiol. 2002;90:111-34.

8. Ye H, Xing F, Yang J, Lo SK, Lau RW, Chen JH, et al. High index of suspicion for brucellosis in a highly cosmopolitan city in southern China. BMC Infect Dis. 2020;20(1):22.

9. Buzgan T, Karahocagil MK, Irmak H, Baran AI, Karsen $\mathrm{H}$, Evirgen $\mathrm{O}$, et al. Clinical manifestations and complications in 1028 cases of brucellosis: a retrospective evaluation and review of the literature. Int J Infect Dis. 2010;14:e469-78.

10. Demirdağ K, Özden M, Özbay Y, Yüce P, Kalkan A. A case of acute brucellosis with pericardial involvement. J Klimik. 2005;18:77-9.

11. Gatselis NK, Makaritsis KP, Gabranis I, Stefos A, Karanikas K, Dalekos GN. Unusual cardiovascular complications of brucellosis presenting in two men: two case reports and a review of the literature. J Med Case Rep. 2011;5:22.

12. Kaya S, Eskazan AE, Elaldi N. Brucellar pericarditis: a report of four cases and review of the literature. Int J Infect Dis. 2013;17:e428-32.

13. Zorlu G, Uyar S, Ozer H, Esin M, Kir S, Tokuc A, et al. A case of brucellosis with a rare complication: pericarditis. Eur J Case Rep Intern Med. 2017;4(1):000471.

14. Sabzi F, Faraji R. Brucella pericarditis: a forgotten cause of chest pain. Caspian J Intern Med. 2017;8(2):116-8. 